Original article

\title{
Cost-effectiveness of surgical mask, N-95 respirator, hand-hygiene and surgical mask with hand hygiene in the prevention of COVID-19: Cost effectiveness analysis from Indian context
}

\author{
Bhavani Shankara Bagepally *, Madhumitha Haridoss, Meenakumari Natarajan, \\ Kathiresan Jeyashree, Manickam Ponnaiah
}

Health Technology Assessment Resource Centre, ICMR- National Institute of Epidemiology, Chennai, India

\section{A R T I C L E I N F O}

\section{Keywords:}

Cost-effectiveness

Cost-utility

COVID-19

Hand hygiene

Markov

Mask

Respirator

SARS-CoV-2

\begin{abstract}
A B S T R A C T
Introduction: In the absence of specific treatment, preventive strategies are of paramount importance in management of coronavirus disease 2019(COVID-19) pandemic. We estimated cost-effectiveness of nonpharmacological interventions such as hand-hygiene, surgical-mask N-95 respirators and surgical mask in general population.

Methods: We performed a decision tree and markov-model based economic evaluation. We estimated total costs and outcomes from public payer's perspective, based on information available through systematic literature search on relative intervention effect during early pandemic phase. We estimated outcomes as number COVID-19 prevented and Quality Adjusted life year (QALY) over one-year time-horizon with one-day cycle-length. Incremental cost effectiveness ratios (ICER) was calculated multiple sensitivity analyses were applied to assess parameter uncertainty.

Results: Use of surgical mask with hand hygiene, fit tested N-95 respirator, surgical-mask, non-fit tested N-95 and hand-hygiene interventions prevented additional 1139, 1124, 1121, 1043 and 975 COVID-19 cases per-million as compared to using none. Additional costs incurred (in billion) were ₹29.78 (\$0.40), ₹148.09 (\$1.99), ₹72.51 (\$0.98), ₹26.84 (\$0.36) and ₹2.48 (\$0.03) as well as additional QALYs gained were 357.4, 353.01, 327.95, 351.52 and 307.04 for surgical mask with hand hygiene, fit-tested N-95, non-fit-tested N-95, surgical mask and hand-hygiene respectively. ICERs with surgical with hand hygiene, hand-hygiene alone, surgical-mask alone, $\mathrm{N}$ 95 respirator fit and non-fit test were 83.32(\$1.12), 8.07(\$0.11), 76.36(\$1.03), 419.51(\$5.65) and 221.10 (\$2.98) million ₹ (\$)/QALY respectively. Results were robust on uncertainty analysis.

Discussion: Among the non-pharmacological interventions to be considered for preventing spread of COVID-19, hand hygiene was cost-effective and avoidance of use of surgical masks and respirators by the general public could save resources.
\end{abstract}

\section{Introduction}

Recently the world has experienced coronaviruses related outbreaks namely severe respiratory distress syndrome (SARS), middle east respiratory syndrome (MERS) since 2003 and currently by a novel coronavirus (SARS-CoV-2) leading to Coronavirus disease 2019 (COVID-19) since December 2, 019. ${ }^{1}$ COVID-19 was initially identified as an outbreak of viral pneumonia in the Wuhan province of China. ${ }^{2}$ COVID-19 spread across the globe and is currently turned into a pandemic situation. ${ }^{3,4}$ Existing evidence suggests that SARS-CoV-2 spreads person-to-person through respiratory droplets (coughing or sneezing), fomites (viable virus on surfaces), and contacts. ${ }^{5}$ All COVID-19 initially can be asymptomatic and later presents with respiratory symptoms, fever, cough, sore throat, shortness of breath, headache as well as diarrhea. ${ }^{6}$ These symptoms usually appear 2-14 days after exposure. ${ }^{5}$

The countries are struggling to fight the spread of the pandemic through many strategies since there is no vaccine yet available for

\footnotetext{
* Corresponding author. ICMR-National Institute of Epidemiology Co-ordinator, Health Technology Assessment Resource Centre, ICMR-NIE R-127, Tamil Nadu Housing Board, Phase I and II, Ayapakkam, Chennai, 600077, India.

E-mail addresses: bagepally.bs@gov.in, bshankara@gmail.com (B.S. Bagepally).
} 
COVID-19. Reliable public health strategies to prevent disease spread include contact tracing, self-isolation or quarantine. World Health Organization (WHO) and the US Centers for Disease Control and Prevention (CDC) USA recommend non-pharmacological interventions to reduce viral transmission in the community and health care settings. These non-pharmacological interventions include the use of personal protective equipment (PPE) such as wearing surgical masks, respirators, and maintenance of hand hygiene, which have proven to be effective in preventing the disease transmission during previous H1N1 influenza, SARS epidemics across the globe. ${ }^{7}$ In fact, studies during the SARS outbreak substantiated the use of surgical masks for health care workers, visitors, and quarantine of contacts of known SARS patients, which reduced the secondary attack rate. Another study on SARS illustrated that the surgical and N95 masks were both effective in significantly reducing the risk of infection ${ }^{8}$; however, did not confer $100 \%$ protection against infection but supported that it may reduce the initial degree of exposure to the virus. ${ }^{9}$ Similarly, for swine flu, routine use of surgical masks along with hand hygiene has been identified to be of use in all clinical settings in dropping the risk of infection. However, it also observed that the use of such PPEs doesn't confer $100 \%$ protection against SARS. ${ }^{9}$ It is also indicated that improper use of PPEs even among medical care workers as well the general population leads to an increase in risk for COVID-19 and contributes to the transmission of pathogens. ${ }^{10}$

Although the use of PPE could significantly reduce the transmission to a considerable amount, due to the pandemic nature of COVID-19, resources need to be efficiently used. Further, in resource-limited and large countries like India, disproportionate use PPEs by the population could lead to a mismatch in demand and supply and could lead to a shortage of PPEs for the needy, especially for healthcare workers. In addition, there is no previous research that investigated the costeffective analysis of surgical masks, N95 respirator (fit and non-fit tested), and hand hygiene in the prevention of COVID-19 in India. Therefore, we examined the cost-utility of use of surgical mask with hand hygiene, hand hygiene alone, surgical mask alone, and N95 respirator (fit tested and non-fit tested) from public payers' perspective in preventing COVID-19 in the general population whose results would guide the policymakers while planning interventions at the national level.

\section{Methods}

\subsection{Cost-utility and cost-effectiveness analysis}

We conducted a cost-utility analysis (CUA) and cost-effectiveness analysis (CEA) using the decision-analytic Markov model to calculate and compare the costs and outcomes (QALY and Cases prevented for CUA and CEA respectively) of using non-pharmacological interventions such as surgical mask, N95-respirator (fit tested and non-fit tested), hand hygiene and surgical mask with hand hygiene compared to using no intervention in the prevention of COVID-19 infection among the general population. The general population has been chosen for this study because COVID-19 being a pandemic, and had different risk of infection among different age groups as people with comorbidities were likely to get infected more than people without any pre-existing disease. Hence use of non-pharmaceutical interventions has been suggested among the general population for disease prevention. We modeled over one-year time horizon from a public payers' perspective, with no discounting as the time horizon is one year. We measured the incremental costeffectiveness ratio (ICER) as Indian Rupees (INR) per quality-adjusted life-year (QALYs) gained. We applied Gross Domestic Product (GDP) based on WHO guideline for willingness to pay threshold, and considered ICER of less than one GDP as highly cost-effective, one-to-three GDP as cost-effective, and more than three GDP as not cost-effective. ${ }^{11}$ Thus, India's GDP per capita of INR 1,42,719 has been considered the cost-effectiveness threshold value per QALY gained. ${ }^{12}$

\subsection{Model overview}

\subsubsection{Decision tree}

A decision tree is a tree-like model of various decisions and their possible consequences. In our study, the decision tree included 6 arms of decisions including the use of surgical masks, N-95 respirator (fit tested), $\mathrm{N}-95$ respirator (non-fit tested), hand hygiene, surgical mask with hand hygiene, and no interventions (not using any of the NPIs) by the general population. Further, for N-95 respirator intervention, we considered both fit tested, and non-fit tested scenarios as the general population may off-label purchase these respirators and use them without conducting proper fit-test for its appropriate use. With the use of any of these interventions that provide relative protection compared to none was incorporated within the Markov model for COVID-19 disease state (Fig. 1).

\subsubsection{Markov model}

A Markov model is a stochastic model which is used to model the probabilities of different states and the rate of transitions between the states, which might differ in the costs and utility. Our model structure consisted of seven health states - Normal (N), Quarantine (Q), Mild (M), Severe (S), Critical (C), Recovery (R), and Death (D) (Fig. 2). We assumed that the general population cohort as enters into the model at normal state, upon administration of any of interventions, might move

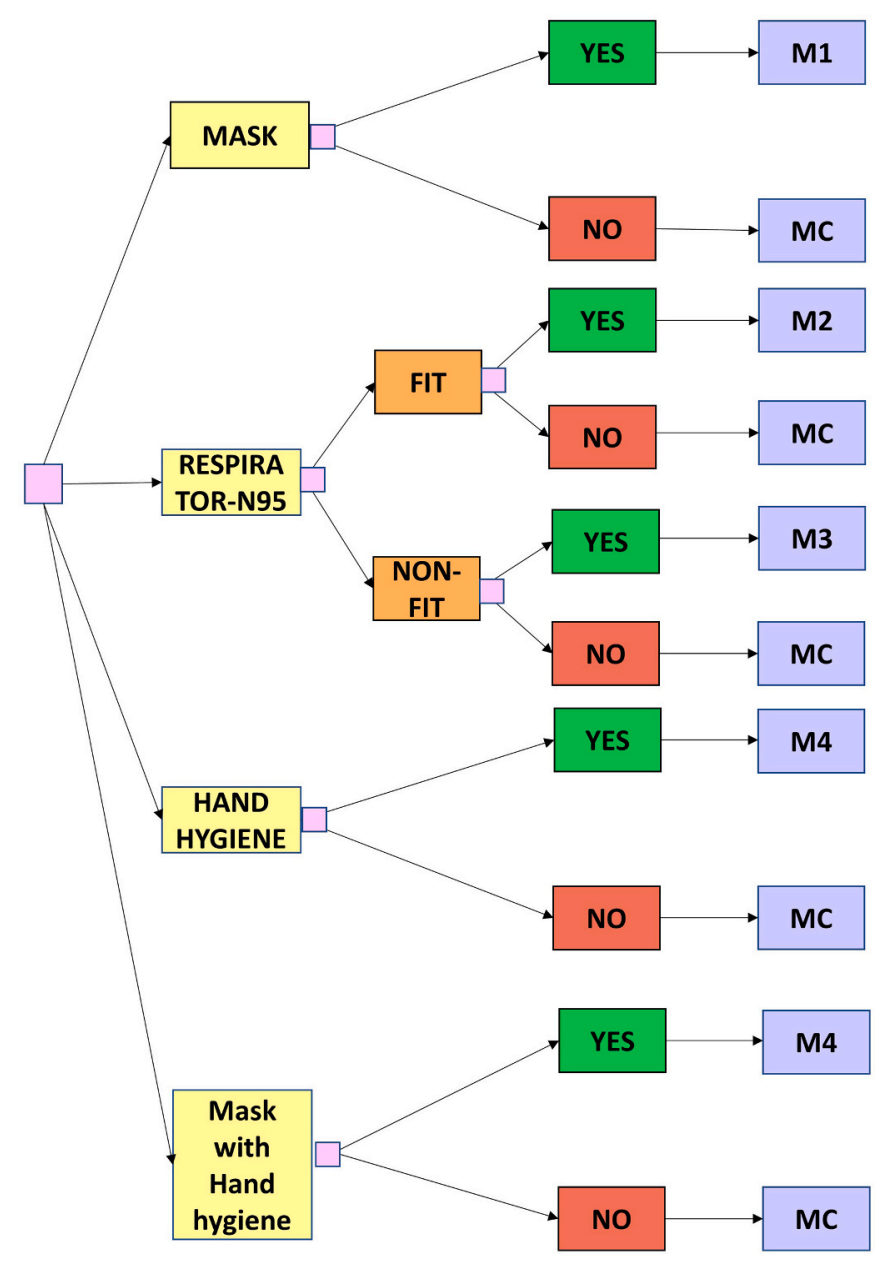

Fig. 1. Schematic diagram of the Decision tree model

Caption: A model cohort of 1 Million population enters the model who either use mask/respirator (fit tested)/respirator (non-tested)/hand hygiene intervention [YES\} and enter the markov model M1/M2/M3/M4 respectively or not use any of the interventions [NO] and enter the markov model for no intervention (MC). 


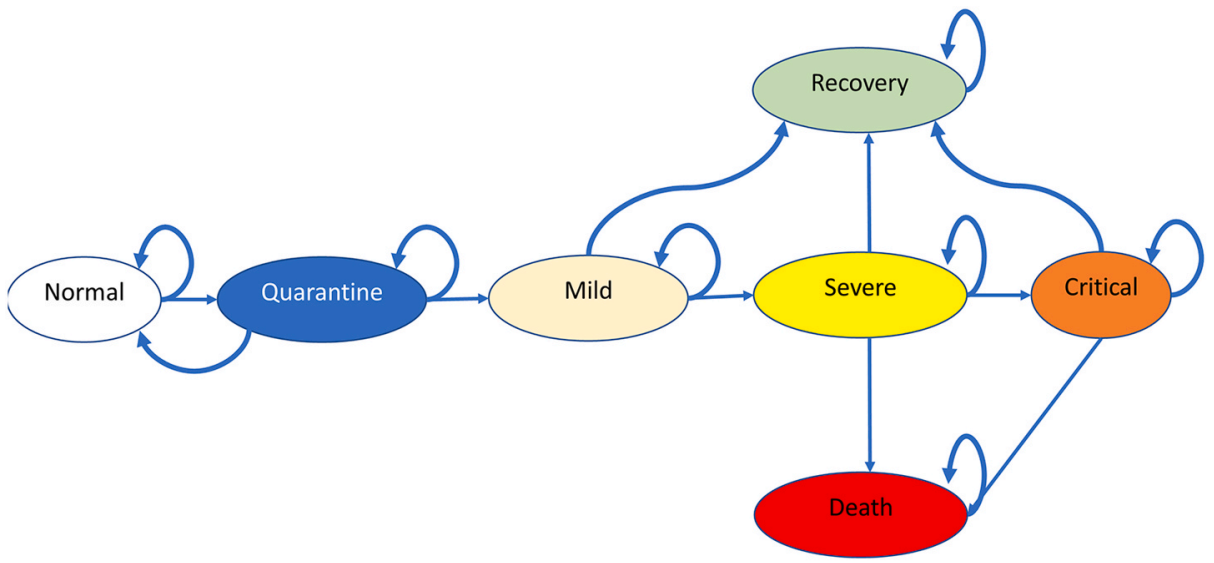

Fig. 2. Schematic diagram of the Markov model Caption: The model comprises of seven health states - Normal (N), Quarantine (Q), Mild (M), Severe (S), Critical (C), Recovery (R) and Death (D) where the model cohort of 1 million population enters into the model at normal state, upon administration of any of interventions, might move to subsequent states. A cycle length of one day and time horizon of 1 year has been considered. to subsequent states. We applied a cycle length of one day, which would run for 365 cycles to represent a one-year time horizon. We assumed that from the normal state, the susceptible individuals would move to a state of quarantine. Individuals who tested negative for COVID-19 in quarantine state would move back to the normal state. Individuals testing positive for COVID-19 with mild symptoms such as fever and cough and not requiring hospitalization would move to a mild state. The model assumed that from the mild state, individuals who developed respiratory illness such as dyspnea would move to a severe state. Severe individuals who developed further complications, such as acute respiratory distress syndrome, moved to a critical state. Based on the methodological domains and the above assumptions, a spreadsheet model was developed using Microsoft Office Excel 2019 (Microsoft Corp., Redmond, WA) to generate total costs incurred for one year and QALYs gained through cohort simulation.

\subsection{Model input parameters}

All the input parameters used in this model have been summarized in Table 1.

\subsubsection{Clinical data}

The effectiveness of any NPI (surgical mask/respirator/hand hygiene/surgical with hand hygiene) against COVID-19 infection was obtained from the published literature. ${ }^{13}, 14,15,16,17$ The data on probability from published literature was based on a hierarch of evidence-based study designs. Hence, the logical order considered was that of systematic review and meta-analysis followed by randomized controlled trials and that of observational studies. The primary data source for baseline transitional probabilities between the different health states were also obtained from published literature. ${ }^{18,} 19,20$ The epidemiological information about COVID-19 was taken from the WHO report and https://www.worldometers.info/(last accessed on March 12, 2020). ${ }^{20,21}$

\subsubsection{Utility data}

The utility values associated with the model health states were sourced from a quality of life study among ARDS survivors (for mild), confirmed H1N1 cases (for severe), and patients in a critical care unit (for critical) because the Quality of life data for COVID-19 was not available. $^{22,23,24}$ It is known that individuals who are suspected of COVID-19 are quarantined and are usually asymptomatic. Hence the utility of quarantine is assumed to be ' 1 ' in this study.

\subsubsection{Cost data}

We considered direct medical costs (DMC) of treatment and monitoring costs related to laboratory and diagnostic tests, procedures, admissions, and out-patient visits, and pharmacologic therapy. Cost of paracetamol $500 \mathrm{mg}$ (oral), N-95 respirator, cost per out-patient were obtained from National Health System Cost Database for India developed by Post Graduate Institute of Medical Education and Research (PGIMER). ${ }^{25}$ The cost of quarantine was obtained from published literature. ${ }^{26}$ The cost of isolation was obtained from a study which had estimated the direct medical costs of MERS Coronavirus infection. ${ }^{27}$ From the same study, ${ }^{27}$ cost of severe and critical have been derived from the direct medical cost of managing a MERS-CoV patient, which includes cost of room, ICU, isolation, health care worker (HCW) fees, laboratory investigations, and medications; Length of stay of $<5$ days and $\geq 5$ days have been defined as severe and critical cases respectively and costs were calculated accordingly. The cost of the surgical mask and N95-respirator and fit test were obtained as per the market price. ${ }^{28}$ Cost of hand hygiene includes the average cost of hand wash $2 \mathrm{ml} /$ wash $\mathrm{x} 11$ times/day and hand sanitizer $2.5 \mathrm{ml} / \mathrm{rub}$ x 11 times/day ${ }^{29}$; All the costs in the initial country currency were adjusted to the respective currency rates for the year 2019 using country-specific consumer price index values and then converted into INR using the international monetary fund database (https://www.imf.org/external/index.htm).

\subsection{Cost-effectiveness}

The total cost and total QALYs gained for each of the interventions (including no intervention) were calculated for one year. Total cost includes the sum of the cost of COVID-19 testing, intervention (surgical mask/N5 (fit tested)/N95 (non-fit tested)/hand hygiene), quarantine, mild, severe, and critical. For no intervention arm, the cost of intervention is zero. Total QALYs includes the sum of QALYs of the seven health states (Normal, quarantine, mild, severe, critical, recovery, death). Incremental cost/QALY is the difference in the total cost/QALY of intervention (mask/N5 (fit tested)/N95 (non-fit tested)/hand hygiene) and the comparator. ICER is obtained by taking the ratio of incremental cost and incremental QALY.

$I C E R=\frac{\text { Cost of intervention }- \text { Cost of comparator }}{Q A L Y \text { of intervention }-Q A L Y \text { of comparator }}$

The total number of COVID-19 cases are calculated as the sum of mild, severe, critical, recovered and death cases over one-year time horizon and the cases prevented for each of the intervention is obtained as the difference in the total cases between the intervention and comparator. We considered the total number of cases prevented in one year as that of the total number of COVID-19 cases reported in the interventions arm in one year minus the total number of cases in the comparator group in the same year.

\subsection{Uncertainty analysis}

In one-way sensitivity analysis, input parameters are varied one at a 
Table 1

Input parameters used in the model and their sampling distribution for the probabilistic sensitivity analysis.

\begin{tabular}{|c|c|c|c|}
\hline Parameter & $\begin{array}{l}\text { Mean (SE or } \\
95 \% \mathrm{CI})\end{array}$ & Distribution & Source \\
\hline $\begin{array}{l}\text { Probability of infection } \\
\text { with Mask } \\
\text { (SM_Reg_Inf) }\end{array}$ & $\begin{array}{l}0.046 \\
(0.221)\end{array}$ & Beta & $\begin{array}{l}\text { (Offeddu, Yung, Low, } \\
\& \text { Tam, 2017) }\end{array}$ \\
\hline $\begin{array}{l}\text { Probability of infection } \\
\text { with Respirator (fit- } \\
\text { tested) (RF_reg_Inf) }\end{array}$ & $\begin{array}{l}0.043 \\
(0.069)\end{array}$ & Beta & $\begin{array}{l}\text { (Offeddu et al., } \\
2017)^{13}\end{array}$ \\
\hline $\begin{array}{l}\text { Probability of infection } \\
\text { with Respirator (no fit- } \\
\text { tested) (RNF_reg_Inf) }\end{array}$ & $\begin{array}{l}0.112 \\
(0.345)\end{array}$ & Beta & $\begin{array}{l}\text { (MacIntyre et al., } \\
2011)^{15}\end{array}$ \\
\hline $\begin{array}{l}\text { Probability of infection } \\
\text { with Hand hygiene } \\
\text { (HH_Inf) }\end{array}$ & $\begin{array}{l}0.170 \\
(0.111)\end{array}$ & Beta & $\begin{array}{l}\text { (Saunders-Hastings, } \\
\text { Crispo, Sikora, \& } \\
\text { Krewski, 2017) }^{14}\end{array}$ \\
\hline $\begin{array}{l}\text { Probablility of infection } \\
\text { with Surgical mask } \\
\text { and hand hygiene }\end{array}$ & 0.030 & Beta & $\begin{array}{l}\text { (Wong, Cowling, \& } \\
\text { Aiello, 2014) })^{17}\end{array}$ \\
\hline \multicolumn{4}{|c|}{ Baseline Transitional Probabilities } \\
\hline Stay Normal (P_N) & 0.999 & Beta & 1-(P_N_Q) \\
\hline $\begin{array}{l}\text { Normal to Quarantine } \\
\text { (P_N_Q) }\end{array}$ & $4.13 \mathrm{E}^{-06}$ & Beta & $\begin{array}{l}\text { https://www. } \\
\text { worldometers. } \\
\text { info/(last accessed on } \\
\text { March } 12,2020 \text { ) }\end{array}$ \\
\hline Stay Quarantine (P_Q) & 0.976 & Beta & 1-(P_Q_M + P_Q_N) \\
\hline Stay Mild (P_M) & 0.019 & Beta & $\begin{array}{l}\text { (Wu \& McGoogan, } \\
2020)^{24}\end{array}$ \\
\hline Stay Severe (P_S) & 0.989 & Beta & $\begin{array}{l}\text { 1-(P_S_C + P_S_D + } \\
\text { P_S_R) }\end{array}$ \\
\hline Stay Critical (P_C) & 0.001 & Beta & $\begin{array}{l}\text { (Wu \& McGoogan, } \\
2020)^{24}\end{array}$ \\
\hline Stay Recovery (P_R) & 0.006 & Beta & $\begin{array}{l}\text { https://www. } \\
\text { worldometers. } \\
\text { info/(last accessed on } \\
\text { March 12, 2020) }\end{array}$ \\
\hline $\begin{array}{l}\text { Normal-Quarantine } \\
\text { (P_N_Q) }\end{array}$ & 4.12568E-06 & Beta & $\begin{array}{l}\text { https://www. } \\
\text { worldometers. } \\
\text { info/(last accessed on } \\
\text { March 12, 2020) }\end{array}$ \\
\hline $\begin{array}{l}\text { Quarantine-Normal } \\
\text { (P_Q_N) }\end{array}$ & 0.010 & Beta & $\begin{array}{l}\text { https://www.wor } \\
\text { ldometers.info/cor } \\
\text { onavirus/(as on March } \\
\text { 12, 2020) }\end{array}$ \\
\hline $\begin{array}{l}\text { Quarantine-Mild } \\
\text { (P_Q_M) }\end{array}$ & 0.015 & Beta & $\begin{array}{l}\text { (Wu \& McGoogan, } \\
2020)^{24}\end{array}$ \\
\hline Mild-Severe (P_M_S) & 0.005 & Beta & $\begin{array}{l}\text { (Wu \& McGoogan, } \\
2020)^{24}\end{array}$ \\
\hline Severe-Critical (P_S_C) & 0.006 & Beta & $\begin{array}{l}\text { (Wu \& McGoogan, } \\
2020)^{24}\end{array}$ \\
\hline Severe-Death (P_S_D) & 0.002 & Beta & $\begin{array}{l}\text { (Organization, } \\
2020)^{17}\end{array}$ \\
\hline Critical-Death (P_C_D) & 0.012 & Beta & $\begin{array}{l}\text { (Wu \& McGoogan, } \\
2020)^{24}\end{array}$ \\
\hline Severe-Recovery (P_S_R) & 0.004 & Beta & $\begin{array}{l}\text { (Organization, } \\
2020)^{17}\end{array}$ \\
\hline $\begin{array}{l}\text { Critical-Recovery } \\
\text { (P_C_R) }\end{array}$ & 0.987 & Beta & 1-(P_C_D + P_C) \\
\hline \multicolumn{4}{|l|}{ Utility Parameters } \\
\hline Normal (u_normal) & 1 & & \\
\hline $\begin{array}{l}\text { Quarantine } \\
\text { (u_quarantine) }\end{array}$ & 1 & Normal & Assumed \\
\hline Mild (u_mild) & $\begin{array}{l}0.77 \\
(0.51-0.83)\end{array}$ & Normal & (Brown et al., 2017) $^{19}$ \\
\hline Severe (u_sev) & 0.29 & Normal & $\begin{array}{l}\text { (van Hoek, } \\
\text { Underwood, Jit, } \\
\text { Miller, \& Edmunds, } \\
2011)^{20}\end{array}$ \\
\hline Critical (u_crit) & -0.283 & Normal & $\begin{array}{l}\text { (Edwards, } \\
\text { Wordsworth, \& Clarke, } \\
2012)^{21}\end{array}$ \\
\hline $\begin{array}{l}\text { Cost Parameters } \\
\text { Direct Medical Costs } \\
\text { (DMC), All costs in INR }\end{array}$ & & & \\
\hline $\begin{array}{l}\text { Cost of Quarantine } \\
\text { (c_quarantine) }\end{array}$ & 5317.30 & & \\
\hline
\end{tabular}

Table 1 (continued)

\begin{tabular}{|c|c|c|c|}
\hline Parameter & $\begin{array}{l}\text { Mean (SE or } \\
95 \% \mathrm{CI} \text { ) }\end{array}$ & Distribution & Source \\
\hline & & & $\begin{array}{l}\text { (Mubayi, Zaleta, } \\
\text { Martcheva, \& Castillo- } \\
\text { Chavez, 2010) }\end{array}$ \\
\hline $\begin{array}{l}\text { Cost of Isolation } \\
\text { (c_isolation) }\end{array}$ & 12878.42 & & $\begin{array}{l}\text { (AlRuthia et al., } \\
2019)^{23}\end{array}$ \\
\hline $\begin{array}{l}\text { Cost of Paracetamol } \\
\text { (Oral) }\end{array}$ & 1.04 & & $(\text { India, } 2020)^{22}$ \\
\hline Cost per outpatient & 774.62 & & $(\text { India, } 2020)^{22}$ \\
\hline $\begin{array}{l}\text { Cost of Mild disease (cost } \\
\text { of paracetamol (oral) } \\
+ \text { outpatient }+ \\
\text { isolation) (per person } \\
\text { per day) (c_mild) }\end{array}$ & 13657.20 & & $\begin{array}{l}\text { (AlRuthia et al., 2019; } \\
\text { India, 2020) }\end{array}$ \\
\hline $\begin{array}{l}\text { Cost of severe disease } \\
\text { (c_sev) (per person per } \\
\text { day) }\end{array}$ & 158446.90 & & $\begin{array}{l}\text { (AlRuthia et al., } \\
2019)^{23}\end{array}$ \\
\hline $\begin{array}{l}\text { Cost of critical disease } \\
\text { (c_crit) (per person per } \\
\text { day) }\end{array}$ & 207398.64 & & $\begin{array}{l}\text { (AlRuthia et al., } \\
2019)^{23}\end{array}$ \\
\hline $\begin{array}{l}\text { Cost of surgical mask ( } 3 \\
\text { nos per person per } \\
\text { day) (c_Mask) }\end{array}$ & 75 & & $\left(\right.$ Indiamart, 2020) ${ }^{26}$ \\
\hline $\begin{array}{l}\text { Cost of N95 respirator ( } 2 \\
\text { nos per person per } \\
\text { day) (c_Resp 95) }\end{array}$ & 200 & & $\left(\right.$ Indiamart, 2020) ${ }^{26}$ \\
\hline $\begin{array}{l}\text { Cost of fit-test (per test)) } \\
\text { (c_fit test) }\end{array}$ & 207.20 & & $\left(\right.$ Indiamart, 2020) ${ }^{26}$ \\
\hline $\begin{array}{l}\text { Cost of Hand hygiene } \\
\text { (per person per day) } \\
\text { (c_HH) }\end{array}$ & 8.04 & & $\left(\right.$ Ahmed, 2007) ${ }^{27}$ \\
\hline $\begin{array}{l}\text { Cost of COVID-19 testing } \\
\text { (per person per test) } \\
\text { (c_testing) }\end{array}$ & 4000 & & $\begin{array}{l}\text { Expert Opinion } \\
\text { (National Institute of } \\
\text { Virology, Pune) }\end{array}$ \\
\hline
\end{tabular}

time by which the highest influential parameter to which the ICER is sensitive is determined. We have conducted a one-way sensitivity analysis by using $25 \%$ higher and lower values of all the transitional probabilities as well as cost and utility values as reported as tornado diagrams. Probabilistic sensitivity analysis (PSA) is done using Monte Carlo simulation, which involves running the model 1000 times using randomly sampled parameter values through which the uncertainty in the prediction would be determined. We conducted a probabilistic sensitivity analysis by varying mainly the transitional probabilities within their data distribution. We used beta distribution for the transitional probabilities. Due to the limited availability of cost information, we have not varied the costs in PSA.

Cost of severe and critical have been derived from the direct medical cost of managing a MERS-CoV patient, which includes the cost of room charges, ICU, isolation, HCW fees, laboratory investigations, and medications; Length of stay of $<5$ days and $\geq 5$ days have been defined as severe and critical cases respectively; Cost of hand hygiene included the average cost of hand wash $2 \mathrm{ml} /$ wash $\mathrm{x} 11$ times/day and hand sanitizer $2.5 \mathrm{ml} / \mathrm{rub} \times 11$ times/day;

\section{Results}

\subsection{Cost-effective analysis}

Based on a probabilistic approach, from the health system perspective, the use of non-pharmacological interventions compared to using no intervention estimated to incur an additional cost of (in billion) ₹29.78 ( $\$ 0.40$ ) for the surgical mask with hand hygiene, ₹148,09 (\$1.99) for N95 respirator (fit tested) followed by ₹72.51 (\$0.97) for non-fit tested, ₹26.84 (\$0.36) for surgical mask alone and ₹2.48 (\$0.03) for handhygiene alone. Additional QALYs gained were 357.4 (surgical mask with hand hygiene), 353.01 (N-95 fit), 351.52 (surgical mask alone), 327.95 (N-95 non-fit), and 307.04 (hand hygiene alone). ICERs for the 
surgical mask with hand hygiene, hand-hygiene alone, surgical-mask alone, N-95 respirator fit tested and non-fit test were 83.32 (\$1.12), 8.07 (\$0.11), 76.36 (\$1.03), 419.51 (\$5.65), and 221.10 (\$2.98) million ₹ (\$)/QALY respectively. The ICER shows that from the health system perspective, implementation of non-pharmacological interventions such as hand hygiene, surgical mask, N-95 respirator (fit tested and non-fit tested), and surgical mask with hand hygiene among the general population for the prevention of COVID-19 was not cost-effective in India as they exceeded the three times cost-effectiveness threshold of ₹ $1,42,719$ (\$1921). However, use of a surgical mask with hand hygiene, fit-tested N-95 respirator, surgical-mask, non-fit tested N-95, and hand-hygiene interventions prevented 1139, 1124, 1121, 1043, and 975 COVID-19 cases per 1 million population respectively as compared to using no NPIs (Table 2).

\subsection{One-way sensitivity analysis}

In the Markov model for the surgical mask, among all input parameters varied, the ICER results were most sensitive to variations in the transitional probabilities (quarantine to normal, quarantine to mild, normal to quarantine, staying in quarantine), utilities (quarantine and normal) and cost (surgical mask) (Fig. 3a). On the other hand, the model estimates were negligibly sensitive with respect to variations in the odds of getting infected with wearing a mask, transitional probabilities (severe to critical, mild to severe, mild to recovery and staying in severe), and utility (severe) and costs (severe, testing, quarantine) With respect to the Markov model for respirator (fit-tested), the ICER results were most sensitive to variations in the utility of normal, transitional probabilities (severe to critical, severe to recovery and severe to death) The model estimates were negligibly sensitive with respect to variations in the transitional probabilities (severe to critical, mild to severe, mild to recovery and staying in severe) and costs (quarantine, isolation, testing, mild and severe) (Fig. 3b). Whereas in the model for respirator (non-fit tested), the ICER results were highly sensitive to variations in utility of normal, transitional probabilities (normal to quarantine and quarantine to mild) and negligibly sensitive to variations in the transitional probabilities (severe to critical, severe to recovery and severe to death) and costs (per out-patient, isolation, mild, severe, testing and quarantine) (Fig. 3c). In the Markov model for hand hygiene, ICER results were highly sensitive to variations in utility of normal, transitional probabilities (normal to quarantine and quarantine to mild), moderately sensitive to variations in transitional probability of staying severe and costs (quarantine and testing) whereas negligibly sensitive to variations in costs (per out-patient, isolation, mild and severe) and transitional probabilities (critical to death, staying at mild and mild to severe) (Fig. 3d). Finally, in the Markov for surgical mask with hand hygiene, ICER results were highly sensitive to variations in the utility of quarantine, transitional probabilities (quarantine to normal and mild to recovery) and odds of not getting infected with surgical mask plus hand hygiene and negligibly sensitive to variation in the cost of isolation
(Fig. 3e). One-way sensitivity analysis results of total infected cases and cases prevented for each of the interventions has been given as supplementary figures (Supp. Figs. S1 \& S2).

\subsection{Probabilistic sensitivity analysis}

According to the Monte Carlo simulation with 1000 simulations (Fig. 4) majority of ICER plots appear at the upper-right quadrant of the plane extending to form an ellipsoid shape, which implies that ICERs were not cost-effective and a positive correlation between incremental cost and incremental outcomes.

\section{Discussion}

In the absence of published studies on the cost-effectiveness of preventive measures of surgical mask with hand hygiene, hand hygiene alone, use of surgical masks alone, and N-95 respirator for COVID-19 as compared to no intervention, we evaluated the same in the Indian context, probably the first of its kind. We observed that none of these interventions were cost-effective, considering the WHO based willingness to pay threshold. Among the interventions, hand hygiene appeared to be less expensive as compared to other interventions but with similar effectiveness compared to the other expensive options. However, the use of surgical mask with hand hygiene prevented the maximum number of deaths due to COVID-19 in our model.

Though the interventions that have been considered in this study have shown clinical effectiveness as evidenced by additional QALYs gained and the number of cases prevented with the use of these interventions, none of them were cost-effective probably due to higher costs of interventions as it is provided to all the population and borne by the public payer with relatively lower effectiveness of the intervention in preventing the infection. With the enhanced production of surgical and N95 masks by Indian manufacturers, it is now possible to get these interventions at a much lower cost $\backslash$. However even with ten times lower cost of N95 masks, it is still not cost-effective probably due to lower effectiveness. In order to reserve the resources (surgical and N95 masks) for front line health care workers, CDC recommends the use of cloth face masks among general public. ${ }^{30}$ Although the efficacy of cloth masks compared to medical grade masks is minimal, its efficacy is relatively high with multiple layers of hybrid fabrics and encouraged to be used in crowded indoor, and outdoor public spaces involving physical proximity to prevent the spread of SARS-CoV-2 infection. ${ }^{31,32}$

In our study, hand hygiene is predicted to effectively prevent COVID19 in the population and is less expensive compared to the use of surgical masks/respirators though not cost-effective. Our findings are supported by previous studies that denote washing hands for at least $20 \mathrm{~s}$ with soap and water or using a hand sanitizer which contains $60 \%$ alcohol $^{5}$ ensures proper hand hygiene which can potentially degrade most of the coronaviruses including SARS-CoV, MERS-CoV, and SARS-CoV-2 and has shown significant effect in reducing the surface transmission of these

Table 2

Cost-effectiveness results.

\begin{tabular}{|c|c|c|c|c|c|c|}
\hline & Mask with hand hygiene & Hand hygiene & Mask & Respirator (fit-tested) & Respirator (non-fit tested) & No Intervention \\
\hline Total Cost (₹ in billions) & $30.32(\$ 0.4)$ & $3.02(\$ 0.04)$ & $27.38(\$ 0.36)$ & $148.63(\$ 2.0)$ & $73.05(\$ 0.98)$ & $0.54(\$ 0.007)$ \\
\hline Total QALY & $9,99,989$ & $9,99,938$ & $9,99,983$ & $9,99,985$ & $9,99,959$ & $9,99,632$ \\
\hline Incremental Cost ${ }^{\mathrm{a}}$ ( $₹$ in Billions) & $29.78(\$ 0.40)$ & $2.48(\$ 0.03)$ & $26.84(\$ 0.36)$ & $148.09(\$ 1.99)$ & $72.51(\$ 0.98)$ & - \\
\hline Incremental $\mathrm{QALY}^{\mathrm{a}}$ & 357.4 & 307.04 & 351.52 & 353.01 & 327.95 & - \\
\hline ICER $^{\mathrm{a}}$ (₹ Millions/QALY) & $83.32(\$ 1.12)$ & $8.07(\$ 0.11)$ & $76.36(\$ 1.03)$ & $419.51(\$ 5.65)$ & $221.10(\$ 2.98)$ & - \\
\hline ICER $^{\mathrm{b}}$ (₹ in Billions/QALY) & $0.54(\$ 0.01)$ & - & $0.55(\$ 0.01)$ & $3.17(\$ 0.04)$ & $3.35(\$ 0.05)$ & - \\
\hline Total Cases (per Million) & 36.15 & 199.99 & 54.10 & 50.39 & 131.94 & 1175.19 \\
\hline Cases prevented $^{\mathrm{a}}$ (per Million) & 1139 & 975 & 1121 & 1125 & 1043 & - \\
\hline Cases prevented $^{\mathrm{b}}$ (per Million population) & 164 & - & 146 & 150 & 68 & - \\
\hline Total Deaths (per Million population) & 2.27 & 12.6 & 3.40 & 3.17 & 8.31 & 74.04 \\
\hline
\end{tabular}

a Compared to no intervention.

b Compared to Hand hygiene. 


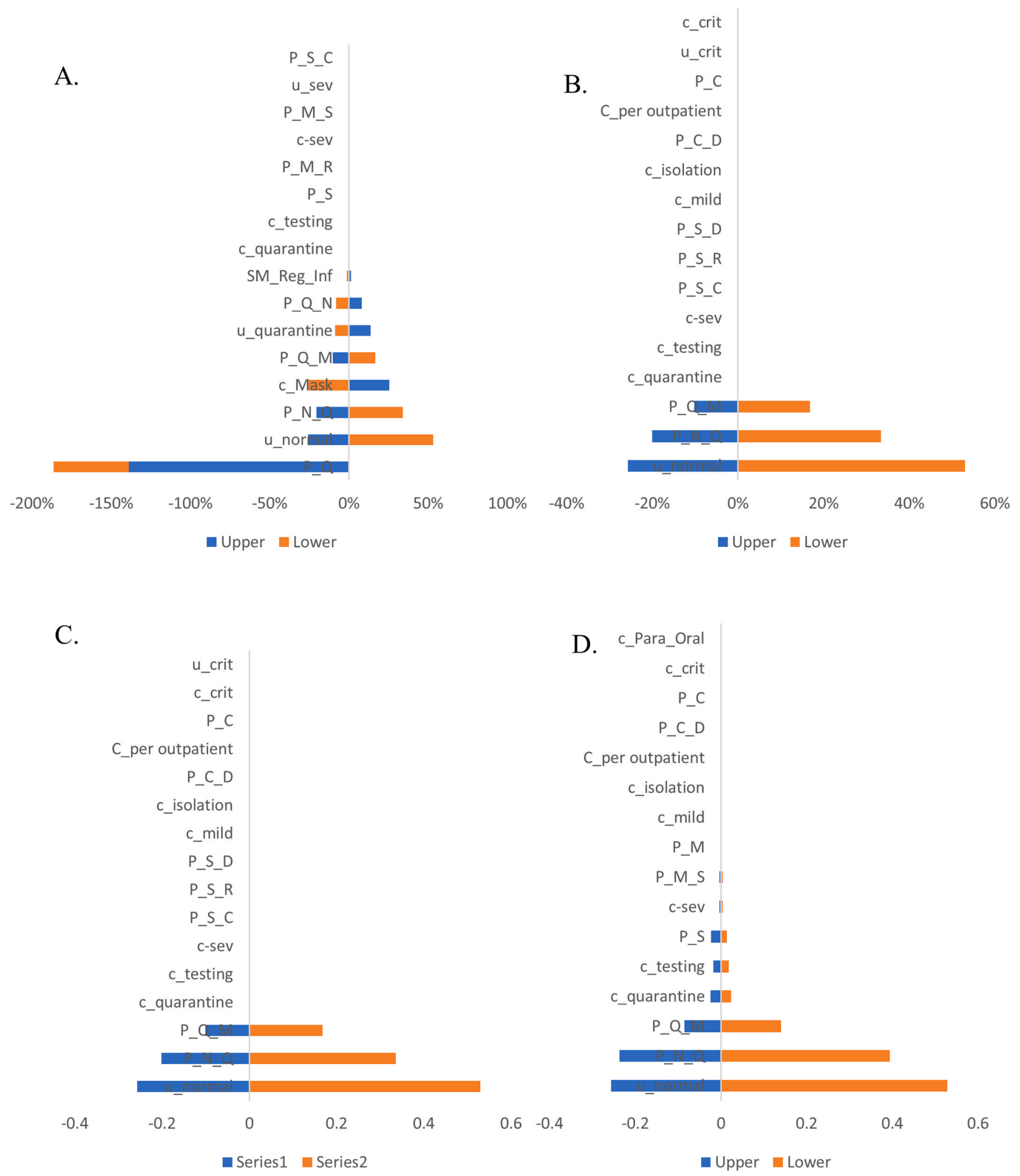

Fig. 3. One-way sensitivity analysis for ICER from a publicly-funded health system perspective

Caption: One-way sensitivity analysis conducted by using $25 \%$ higher and lower values of all the transitional probabilities, cost and utility values. The blue bars show the effect on the ICER of applying the lower limit $(-25 \%)$ of specific parameter, while the yellow bars show the effect on the ICER of applying upper limit $(+25 \%)$ of the specific parameter. 


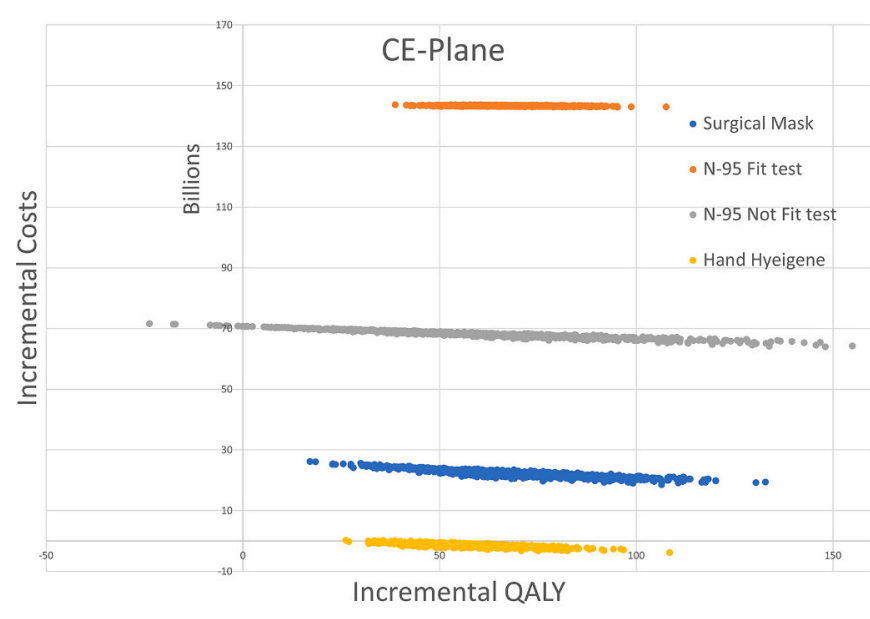

Fig. 4. Cost-effectiveness (CE) plane from a publicly-funded health system perspective

Caption: Cost-effectiveness plane showing Monte Carlo simulation with 1000 replications of the ICER plots of the interventions (mask/N95 respirator (fit)/ N95respirator (non-fit)/hand hygiene with most of the plots in the upper-right quadrant of the plane denoting the interventions are not cost-effective.

diseases. ${ }^{33}$ However, a recent systematic review conducted on the effectiveness of hand hygiene practices in preventing influenza virus infection in a community setting concluded that it is difficult to determine its effectiveness in a community setting because of the inconsistency in results from different studies. ${ }^{34}$

Similar to hand hygiene, the use of surgical mask, respirator, and surgical mask with hand hygiene has also shown significant clinical effectiveness though not cost-effective. In the published literature, number of studies have evaluated effectiveness of mask/respirator to prevent the transmission of respiratory infections. Further, such protection was mostly found among health care workers who practiced wearing surgical mask with hand hygiene with alcohol-based hand rub during patient care. ${ }^{35}$ Seminal contributions have been made by Yit et al. $^{36}$ that the attack rate of HCWs who were rescuing severe SARS patients without any PPE was $62 \%$. This is an important finding in the understanding that the more the protective measures were used higher the protective effect. The novel finding is that it could reach $100 \%$ if surgical masks, gowns, gloves, goggles, footwear, handwashing, and disinfecting were all used simultaneously. A cluster-randomized trial of surgical face mask use in households in controlling the transmission of respiratory viral infections also substantiated its significance in preventing disease transmission from household contacts. ${ }^{37}$

It is important to note that published studies on the effectiveness of non-pharmacological interventions in preventing the transmission were mostly done in healthcare settings. Population-based studies, as well as cost-effectiveness of the interventions, are limited. ${ }^{38}$ In a previous cost-utility analysis done in a health care setting which compared the continuous use of respirators to masks, the incremental cost to prevent a chronic respiratory illness (CRI) case in a HCW ranged from US \$490$\$ 1230$, which was said to be in an acceptable range but the cost-effectiveness of the same was said to be dependent on the willingness to pay threshold which varies between the countries. However, it has been concluded that in a highly pathogenic pandemic, respirator use in HCWs would likely be a cost-effective intervention. ${ }^{39}$ However, in our study we have compared the use of interventions to using none in general population. If use of these interventions to prevent COVID-19 in a health care setting in India would-be cost-effective needs to studied. The sensitivity analysis results are robust, indicating that even on variation of individual parameters, the observed results were valid. Further results of sensitivity analysis showed that the ICER results were most sensitive to variations in transitional probabilities and cost. The robustness of the model can thus be increased with more accurate transitional probabilities and cost details of COVID-19, which is currently difficult to obtain due to limited published pieces of evidence on the same.

Our study has several limitations. Firstly, we conducted this study early in the pandemic, and hence primary country-specific literature, including the utility and cost data specific to novel virus SARS-CoV-2, were limited. Thus, we had to generate such estimates of costs and outcomes for the model based on available information from studies done in settings outside India. We have, however, adjusted the estimates for currency. Secondly, our assumption of public payers' perspective for the non-pharmacological interventions studied can be debatable, at least for hand-hygiene. Many Indian States provide a significant amount of subsidy for the common utilities such as electricity, water supply, including the basic supply of masks, hand sanitizers, public handwashing facilities, and other utilities. Further, apportioning contributions specific to hand washing or that of surgical masks is difficult. Hence, though oversimplified, we resorted to analyze based on public payers' perspective. It is possible that it could have led to an overestimation of the effects. Additionally, as we have adapted public payer's perspective we could not consider the cost incurred due to loss of wages due to COVID-19 which could be an important parameter. Thirdly we have considered a shorter time horizon (1 year) and hence have not modeled various co-morbid conditions within each state which is seen as a limitation. However in the model which we have used is an overall crude death rate which is inclusive of varying death rate among individuals with pre-existing comorbid conditions and COVID-19.

Despite such limitations, we believe such information may guide policymakers while planning interventions at the national level, especially in the early phase of the pandemic. The information on the risk of infection as such is also emerging from various settings. At the time of our study, India has just started experiencing the pandemic, and hence, the risk of infection was not available. However, as a thumb rule, many countries are using information available from each other. At a broader level, this may have led to an overestimation of the outcomes studied.

Based on the findings, we conclude that among the nonpharmacological interventions to be considered for preventing the spread of COVID-19, hand hygiene was cost-effective, and avoidance of the use of surgical masks and respirators by the general public could save resources. Therefore, we recommend the authorities at all levels to actively promote population-level hand hygiene practices.

\section{Source of funding}

This study did not receive any funding specific for this work but ICMR-NIE HTA Resource Centre is supported by Dept. of Health Research, Govt. of India and Funders has no role in the study.

\section{Data availability}

All data generated or analysed data during this study are included in this published article (and its supplementary files).

\section{Author's contribution}

Bhavani Shankara Bagepally: Study conception and design, Acquisition of data, Analysis and interpretation of data, Drafting of manuscript, Critical revision.

Madhumitha H: Acquisition of data, Analysis and interpretation of data, Drafting of manuscript, Critical revision.

Meena Kumari N: Acquisition of data, Analysis and interpretation of data, Critical revision.

Jeyashree Kathiresan: Interpretation of data, Critical revision.

Manickam Ponnaiah: Interpretation of data, Critical revision.

\section{Declaration of competing interest}

The authors do no declare any conflicts of interest. 


\section{Appendix A. Supplementary data}

Supplementary data to this article can be found online at https://doi. org/10.1016/j.cegh.2021.100702.

\section{References}

1 El Zowalaty ME, Jarhult JD. From SARS to COVID-19: a previously unknown SARSrelated coronavirus (SARS-CoV-2) of pandemic potential infecting humans - call for a One Health approach. One Health. 2020;9:100124. https://doi.org/10.1016/j. onehlt.2020.100124.

2 Cowling BJ, Aiello A. Public health measures to slow community spread of COVID19. J Infect Dis. 2020. https://doi.org/10.1093/infdis/jiaa123.

3 Basile C, Combe C, Pizzarelli F, et al. Recommendations for the prevention, mitigation and containment of the emerging SARS-CoV-2 (COVID-19) pandemic in haemodialysis centres. Nephrol Dial Transplant. 2020. https://doi.org/10.1093/ndt/ gfaa069.

4 Cucinotta D, Vanelli M. WHO declares COVID-19 a pandemic. Acta Biomed. 2020;91 (1):157-160. https://doi.org/10.23750/abm.v91i1.9397.

5 Desai AN, Patel P. Stopping the spread of COVID-19. J Am Med Assoc. 2020. https:// doi.org/10.1001/jama.2020.4269.

6 Abdi M. Coronavirus disease 2019 (COVID-19) outbreak in Iran; actions and problems. Infect Control Hosp Epidemiol. 2020:1-5. https://doi.org/10.1017/ ice.2020.86.

7 Bedford J, Enria D, Giesecke J, et al. COVID-19: towards controlling of a pandemic. Lancet. 2020. https://doi.org/10.1016/S0140-6736(20)30673-5.

8 Seto WH, Tsang D, Yung RW, et al. Effectiveness of precautions against droplets and contact in prevention of nosocomial transmission of severe acute respiratory syndrome (SARS). Lancet. 2003;361(9368):1519-1520. https://doi.org/10.1016/ s0140-6736(03)13168-6.

$9 \mathrm{Lu}$ YT, Chen PJ, Sheu CY, Liu CL. Viral load and outcome in SARS infection: the role of personal protective equipment in the emergency department. J Emerg Med. 2006; 30(1):7-15. https://doi.org/10.1016/j.jemermed.2005.03.011.

10 John A, Tomas ME, Hari A, Wilson BM, Donskey CJ. Do medical students receive training in correct use of personal protective equipment? Med Educ Online. 2017;22 (1):1264125. https://doi.org/10.1080/10872981.2017.1264125.

11 Bank TW. https://data.worldbank.org/country/india.

12 RBI) RBoI. https://rbidocs.rbi.org.in/rdocs/Publications/PDFs/1T_HB150920 19EA2B9307F08B4B4AB305B6D25552E76E.PDF.

13 Offeddu V, Yung CF, Low MSF, Tam CC. Effectiveness of masks and respirators against respiratory infections in healthcare workers: a systematic review and metaanalysis. Clin Infect Dis. 2017;65(11):1934-1942. https://doi.org/10.1093/cid/ cix681.

14 Saunders-Hastings P, Crispo JAG, Sikora L, Krewski D. Effectiveness of personal protective measures in reducing pandemic influenza transmission: a systematic review and meta-analysis. Epidemics. 2017;20:1-20. https://doi.org/10.1016/j. epidem.2017.04.003.

15 MacIntyre CR, Wang Q, Cauchemez S, et al. A cluster randomized clinical trial comparing fit-tested and non-fit-tested N95 respirators to medical masks to prevent respiratory virus infection in health care workers. Influenza Other Respir Viruses. 2011;5(3):170-179. https://doi.org/10.1111/j.1750-2659.2011.00198.x.

16 Qifang Bi YW, Mei Shujiang, Ye Chenfei, et al. Epidemiology and Transmission of COVID-19 in Shenzhen China: Analysis of 391 Cases and 1,286 of Their Close Contacts. 2020/1/1.

17 Wong VWY, Cowling BJ, Aiello AE. Hand hygiene and risk of influenza virus infections in the community: a systematic review and meta-analysis. Epidemiol Infect. 2014;142(5):922-932. https://doi.org/10.1017/S095026881400003X.

$18 \mathrm{Wu}$ Z, McGoogan JM. Characteristics of and important lessons from the coronavirus disease 2019 (COVID-19) outbreak in China: summary of a report of 72314 cases from the Chinese center for disease control and prevention. J Am Med Assoc. 2020. https://doi.org/10.1001/jama.2020.2648.

19 Worldometer. https://www.worldometers.info/; 2020. Accessed March 12, 2020.

20 Organization WH. Report of the WHO-China joint mission on coronavirus disease 2019 (COVID-19). https://www.who.int/docs/default-source/coronaviruse/whochina-joint-mission-on-covid-19-final-report.pdf; 2020.

21 Worlometer. https://www.worldometers.info/; 2020. Accessed March 12, 2020.

22 Brown SM, Wilson E, Presson AP, et al. Predictors of 6-month health utility outcomes in survivors of acute respiratory distress syndrome. Thorax. 2017;72(4):311-317. https://doi.org/10.1136/thoraxjnl-2016-208560.

23 van Hoek AJ, Underwood A, Jit M, Miller E, Edmunds WJ. The impact of pandemic influenza $\mathrm{H} 1 \mathrm{~N} 1$ on health-related quality of life: a prospective population-based study. PloS One. 2011;6(3), e17030. https://doi.org/10.1371/journal.pone.0017030.

24 Edwards SJ, Wordsworth S, Clarke MJ. Treating pneumonia in critical care in the United Kingdom following failure of initial antibiotic: a cost-utility analysis comparing meropenem with piperacillin/tazobactam. Eur J Health Econ. 2012;13(2): 181-192. https://doi.org/10.1007/s10198-011-0296-0.

25 India NHSCDf. 2020.

26 Mubayi A, Zaleta CK, Martcheva M, Castillo-Chavez C. A cost-based comparison of quarantine strategies for new emerging diseases. Math Biosci Eng. 2010;7(3): 687-717. https://doi.org/10.3934/mbe.2010.7.687.

27 AlRuthia Y, Somily AM, Alkhamali AS, et al. Estimation of direct medical costs of Middle East respiratory syndrome coronavirus infection: a single-center retrospective chart review study. Infect Drug Resist. 2019;12:3463-3473. https://doi.org/10.2147/ IDR.S231087.

28 Indiamart. https://my.indiamart.com/?back=1. 2020.

29 Ahmed A. Surgical hand scrub: lots of water wasted. Ann Afr Med. 2007;6(1):31-33. https://doi.org/10.4103/1596-3519.55733.

30 CfDCa Prevention. Coronavirus Disease-19: Recommendation Regarding the Use of Cloth Face Coverings, Especially in Areas of Significant Community-Based Transmission; 2020, 2020 https://wwwcdcgov/coronavirus/2019-ncov/prevent-getting-sick/cloth -face-coverhtml\#studies. Accessed December 28, 2020.

31 Sharma SK, Mishra M, Mudgal SK. Efficacy of cloth face mask in prevention of novel coronavirus infection transmission: a systematic review and meta-analysis. $J$ Educ Health Promot. 2020;9:192. https://doi.org/10.4103/jehp.jehp_533_20.

32 Santos M, Torres D, Cardoso PC, et al. Are cloth masks a substitute to medical masks in reducing transmission and contamination? A systematic review. Braz Oral Res. 2020;34:e123. https://doi.org/10.1590/1807-3107bor-2020.vol34.0123.

33 Xiao J, Shiu EYC, Gao H, et al. Nonpharmaceutical measures for pandemic influenza in nonhealthcare settings-personal protective and environmental measures. Emerg Infect Dis. 2020;26(5). https://doi.org/10.3201/eid2605.190994.

34 Moncion K, Young K, Tunis M, Rempel S, Stirling R, Zhao L. Effectiveness of hand hygiene practices in preventing influenza virus infection in the community setting: a systematic review. Can Comm Dis Rep. 2019;45(1):12-23. https://doi.org/10.14745/ ccdr.v45i01a02.

35 Cheng VC, Tai JW, Wong LM, et al. Prevention of nosocomial transmission of swineorigin pandemic influenza virus $\mathrm{A} / \mathrm{H} 1 \mathrm{~N} 1$ by infection control bundle. $J$ Hosp Infect. 2010;74(3):271-277. https://doi.org/10.1016/j.jhin.2009.09.009.

36 Yin WW, Gao LD, Lin WS, et al. [Effectiveness of personal protective measures in prevention of nosocomial transmission of severe acute respiratory syndrome]. Zhonghua Liuxingbingxue Zazhi. 2004;25(1):18-22.

37 MacIntyre CR, Cauchemez S, Dwyer DE, et al. Face mask use and control of respiratory virus transmission in households. Emerg Infect Dis. 2009;15(2):233-241. https://doi.org/10.3201/eid1502.081167.

38 Mukerji S, MacIntyre CR, Newall AT. Review of economic evaluations of mask and respirator use for protection against respiratory infection transmission. BMC Infect Dis. 2015;15:413. https://doi.org/10.1186/s12879-015-1167-6.

39 Mukerji S, MacIntyre CR, Seale H, et al. Cost-effectiveness analysis of N95 respirators and medical masks to protect healthcare workers in China from respiratory infections. BMC Infect Dis. 2017;17(1):464. https://doi.org/10.1186/s12879-0172564-9. 